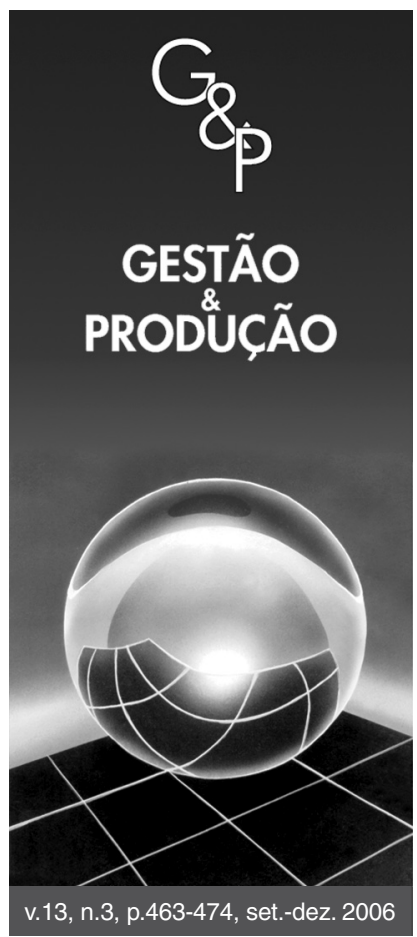

\title{
HÁ VIDA APÓS A MORTE: UM (RE)PENSAR ESTRATÉGICO PARA O FIM DA VIDA DAS EMBALAGENS
}

\author{
Sylmara Lopes Francelino Gonçalves-Dias \\ Escola de Administração de Empresas de São Paulo - EAESP, \\ Fundação Getúlio Vargas - FGV, Rua Ribeiro do Vale, 1058, \\ CEP 04568-003, São Paulo, SP, Brasil, \\ Programa de Ciência Ambiental - PROCAM, \\ Universidade de São Paulo - USP, \\ e-mail: sdias@gvmail.br
}

Resumo

Recebido em 03/7/2006

Aceito em 06/11/2006

Um dos temas ambientais mais destacados na agenda de discussão sobre meio ambiente refere-se aos resíduos sólidos, sobretudo nos grandes centros urbanos. Várias publicações científicas têm tratado de fenômenos relacionados à geração, coleta, disposição e reciclagem do lixo urbano, verificando uma crescente preocupação com o destino da embalagem após o consumo. Este artigo pretende promover um diálogo entre a logística reversa e o ciclo de vida das embalagens; procurando avançar na compreensão das possibilidades, desafios e dilemas da gestão do fim da vida das embalagens. É analisado o caso da reciclagem da embalagem PET (Politereftalato de Etileno), de forma a problematizar os fatores impulsionadores e limitadores da expansão dessa estratégia de gestão ambiental no cenário brasileiro. Com múltiplas aplicações na produção industrial, o PET tornou-se, nos últimos anos, presença constante no cotidiano dos consumidores, colocando importantes desafios para o entendimento da complexa cadeia de reciclagem e das possibilidades de avanço de práticas e políticas de gestão ambiental. Foram adotadas diferentes estratégias para a construção do estudo de caso, envolvendo fontes secundárias produzidas por órgãos públicos e instituições especializadas além de entrevistas semi-estruturadas. Os resultados apontam que, apesar de existirem avanços significativos para o volume reciclado, ainda persistem importantes desafios a serem superados no que diz respeito às normas de regulação da cadeia reversa, às estratégias de inovação tecnológica e gerencial e, sobretudo, às interações dos atores na cadeia. Além disso, o tema pressupõe que seja necessário um aumento do nível de informação da população, eliminação de desperdício desde a concepção, desenvolvimento de tecnologias, responsabilidades compartilhadas, reciclagem, mas, acima de tudo, mudança do padrão do comportamento de consumo da sociedade atual.

Palavras-chave: reciclagem, ciclo de vida de embalagens, embalagem pet, logística reversa, gestão ambiental.

\section{Introdução}

Nos anos 80, houve um crescimento da busca por alternativas para reduzir a quantidade de lixo, verificandose uma preocupação com o destino da embalagem após o consumo (Amadeu et al., 2005; Berthier, 2003; Pieters, 1991). Na verdade, a embalagem tem sido o principal ponto de discussão de políticas públicas e grupos ambientalistas rumo à solução do gerenciamento dos resíduos sólidos urbanos (Fonteyne, 2000; Levy, 2000a; Palha- res, 2003; Williamson, 2000). De um ponto de vista mais amplo, a embalagem não é somente o invólucro para um produto, ela representa a filosofia ambiental da empresa (Wasik, 1996; Woods e Beynon, 2000).

Várias publicações científicas têm analisado fenômenos relacionados à geração, coleta, disposição e reciclagem dos resíduos urbanos (Berthier, 2003; Pieters, 1991). Zanin e Mancini (2004) listam 28 universidades e cen- 
tros de pesquisa brasileiros, com forte concentração na Região Sudeste, que desenvolvem investigações relacionadas à reciclagem e reutilização de resíduos, sobretudo com o foco no desenvolvimento tecnológico. Outra parcela relevante das pesquisas desenvolvidas no ambiente acadêmico analisa políticas públicas de tratamento dos resíduos e atores envolvidos no equacionamento do problema (Amadeu et al., 2005; Grimberg e Blauth, 1998; Jacobi, 2006).

Ao mesmo tempo que no ambiente empresarial as iniciativas da chamada logística reversa parecem adquirir cada vez mais importância para as estratégias corporativas de competitividade sustentada, percebe-se uma lacuna na literatura voltada ao estudo da cadeia de reciclagem e da gestão do fim da vida de embalagem (Leite, 2003; Camargo, Souza, 2005).

Este artigo, portanto, pretende promover um diálogo entre os campos de logística reversa e do ciclo de vida das embalagens; procurando avançar na compreensão das possibilidades, desafios e dilemas da gestão do fim da vida das embalagens. É analisado o caso da reciclagem da embalagem PET (Politereftalato de Etileno), de forma a problematizar os fatores impulsionadores e limitadores da expansão da estratégia de reciclagem na gestão ambiental, considerando-se o cenário brasileiro.

Com múltiplas aplicações na produção industrial, o PET vem se tornando, nos últimos anos, alvo de disputa entre catadores; objeto de interesse por parte de empresas recicladoras e transformadoras; estratégia preferencial de embalagem para indústria alimentícia; e presença constante no cotidiano dos consumidores (Campos, 2000; Pacheco, 2000, Zanin e Mancini, 2004; Xavier e Cardoso, 2005). Ora vista como receptáculo de produtos avidamente consumidos, ora como grande vilã ambiental, ou ainda, como atrativa fonte de renda para os envolvidos em sua reciclagem, a embalagem PET coloca importantes desafios para o entendimento da revalorização ao fim de sua vida e para as possibilidades de avanço de práticas no âmbito da logística reversa.

A preocupação-chave deste artigo está sintetizada na constatação de que: "o fato de projetar embalagens recicláveis não significa que elas serão recicladas!" (Pereira e Santos, 2002). Primeiramente, mostra-se um panorama dos resíduos urbanos brasileiros, com destaque para o papel das embalagens plásticas; a seguir são apresentados desafios em relação à concepção, produção e descarte das embalagens; são apontadas tendências na legislação de alguns países, inclusive na brasileira, em que a responsabilidade pela gestão do fim da vida de embalagem recai sobre produtores. Neste contexto, cresce o papel da logística reversa para equacionar o retorno das embalagens pós-consumo ao ciclo produtivo. Por fim apresenta-se o caso da embalagem PET como forma de evidenciar os fatores limitadores e impulsionadores da estratégia de reciclagem como ferramenta de gestão ambiental no contexto brasileiro.

\section{Embalagens pós-consumo: vilãs do meio ambiente?}

O Brasil produz, por dia, aproximadamente 149 mil toneladas de resíduos sólidos (IBGE, 2002), mas apenas 13,4 mil, ou 9\%, são recicladas, segundo o Informe Analítico da Situação da Gestão Municipal de Resíduos Sólidos no Brasil, do Ministério das Cidades (apud IDEC, 2006). O restante, 135,6 mil toneladas, é destinado a aterros sanitários (32\%), aterros clandestinos ou ruas e terrenos baldios (59\%), causando problemas ao meio ambiente e gerando sérios riscos à saúde pública (IBGE, 2002). No entanto, aproximadamente $35 \%$ desse volume poderia ser reciclado, e outros $35 \%$, transformados em adubo orgânico. Com base em informações do CEMPRE - Compromisso Empresarial para a Reciclagem -, é possível estimar que o Brasil desperdiça, anualmente, mais de 10 bilhões de reais em resíduos sólidos, descontando o que é reciclado (IDEC, 2006).

Dentre os resíduos, o destaque dos últimos anos é para as embalagens plásticas. O consumo de plásticos no Brasil e no mundo vem aumentando há décadas, numa clara demonstração do enorme sucesso conseguido por esse material nas mais variadas aplicações (ABIPLAST, 2006). As características típicas do plástico, como seu baixo custo, baixo peso, boa resistência mecânica, impermeabilidade, transparência, capacidade de coloração e impressão, lhe conferiram trunfos irresistíveis para seu uso massivo na forma de embalagens, tornando-se uma aplicação extremamente importante numa sociedade voltada para o consumo (Barrett e Bickerstaffe, 2000; Piva e Wiebeck, 2004; Santos, 2003; Xavier e Cardoso, 2005).

Em 2005, o setor de embalagem brasileiro movimentou US $\$ 12,8$ bilhões, sendo os plásticos responsáveis por $32,2 \%$, o maior volume entre os materiais utilizados em embalagens (ABRE, 2006). Do total de 4,2 milhões de toneladas de plásticos consumidos no Brasil em 2005, nada menos do que 1,76 milhão de toneladas foram usadas na produção de embalagens, e 462 mil toneladas em produtos descartáveis (ABIPLAST, 2006). Dito em outras palavras: só no ano de 2005 mais de dois milhões de toneladas ou $53 \%$ do plástico consumido no Brasil teve vida útil efêmera e foi para o lixo após algumas semanas de uso.

Portanto, dentre os resíduos sólidos, os plásticos chamam mais atenção devido a total descartabilidade das embalagens e sua resistência à degradação (Santos et al., 2004). Na verdade, a grande maioria dos materiais plásticos utilizados para compor as embalagens de alimentos possui tecnologia para a sua reciclagem (Piva e Wiebeck, 
2004; Zanin e Mancini, 2004). A cada dia, novos conhecimentos são adquiridos, visando um reaproveitamento adequado dos materiais utilizados para a proteção e a segurança do alimento industrializado. Por outro lado, apesar de existir possibilidade técnica para a reciclagem, alguns materiais, como o isopor, são considerados não recicláveis por falta de interesse de mercado (Xavier e Cardoso, 2005; IDEC, 2006).

Um dos plásticos bastante questionados pelos movimentos ambientalistas é o PET, gerando um impasse sobre quem é o responsável pela gestão do fim da vida da embalagem (Kazazian, 2005; Zikmund e Stanton, 1971). Enquanto em alguns países da União Européia esse embate levou a legislação e a própria iniciativa empresarial a assumir a responsabilidade por todo o ciclo de vida dos produtos que gera, em outros países, permanece um vácuo (Levy, 2000b).

Um ponto crítico para as legislações locais em relação às embalagens plásticas tem sido a distribuição de responsabilidades ao longo da cadeia produtiva: o processador da resina, o engarrafador e o distribuidor (Santos et al., 2004). No caso brasileiro, a própria sociedade, por meio de iniciativas como as das cooperativas de catadores de recicláveis e de organizações não-governamentais, assume o ônus e alguns bônus da reciclagem de embalagens. No entanto, permanece o debate sobre o papel da indústria de embalagens, da indústria dos produtos embalados, dos governos e dos consumidores nesse processo.

\section{Ciclo de vida da embalagem: funções, disfunções e refunções}

O desafio das empresas em relação às decisões de projetar e produzir embalagens é extremamente complexo. Por um lado, há que se assegurar que elas obedeçam às exigências legais e às demandas do consumidor, sendo atraentes no ponto-de-venda, eficientes nas linhas de produção e no transporte, eficazes na proteção dos produtos que acondicionam, sem perder de vista o impacto que podem ter sobre o custo final do produto (Levy, 2000a). Além disso, para pensar a funcionalidade dos produtos industriais, é fundamental que seja focalizada a questão do meio ambiente. Não é possível falar de facilidade e de adequação da função de uma embalagem sem considerar os critérios ambientais adotados no seu projeto (Pereira e Santos, 2002).

Inteiramente efêmera, seu destino natural é o descarte (Kazazian, 2005; Santos, 2003; Smith e White, 2000). Desta forma, a embalagem pode ser considerada um poluidor nômade, cada etapa de seu ciclo de vida produz impactos negativos sobre o meio ambiente (poluição, resíduos, nocividades) em diferentes lugares do planeta (Kazazian, 2005; Manzini e Vezzoli, 2002). Daí um duplo desequilíbrio: de um lado, o esgotamento dos recur- sos naturais, de outro um aumento crescente dos resíduos provenientes do consumo.

As etapas devem ser analisadas desde a concepção do produto, porque cada uma contém um potencial de otimização ambiental: na escolha das matérias-primas, das tecnologias e dos processos de fabricação, na organização da logística; em seguida, no contexto de uso e na valorização ao final da vida da embalagem. Neste contexto, Santos e Pereira (1999) apresentam interessante abordagem sobre o ciclo de vida da embalagem, conforme Figura 1.

A Figura 1 representa não somente a função da embalagem, mas também sua disfunção e refunção, identificando três estágios fundamentais no ciclo de vida da embalagem: 1) Concepção e produção: considerando-se o conteúdo a ser embalado (características físico-químicas e conservação), processo de embalagem, material a ser utilizado, produção e transporte; 2) Consumo: são considerados os procedimentos de venda do produto embalado, seu transporte e estocagem. Além disso, leva-se em conta, o consumo do produto embalado e a interface do usuário-embalagem (uso da embalagem, conservação e informação). O descarte da embalagem e sua transformação em lixo fazem parte desta fase; e 3) Pós-consumo: para esta fase consideram-se duas possibilidades. $\mathrm{O}$ reuso da embalagem pelo consumidor ou a reciclagem, incluindo o complexo trabalho de coleta, triagem e revalorização da embalagem. A outra é a redução na origem, pelo uso de menos matéria-prima, projetos de produtos recicláveis e, ainda, alterando o padrão de produção e consumo.

Neste sentido, a função da embalagem propriamente dita, está delimitada entre a fase de concepção e consumo. Durante o consumo, podem-se verificar alguns desvios em sua função principal, como por exemplo, problemas de saúde provocados por contaminação ou pelo descarte inadequado, acarretando a produção de lixo. Estes fatos são denominados disfunção da embalagem. Quando acontece um novo uso para a embalagem após o consumo, as autoras denominam refunção. Ou seja, a

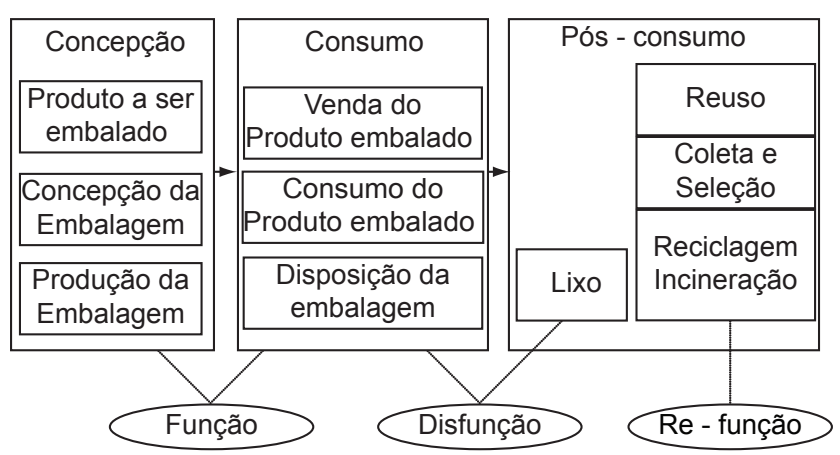

Figura 1. O ciclo de vida da embalagem. Fonte: Santos e Pereira (1999). 
embalagem é reciclada voltando ao ciclo produtivo ou reutilizada para outra finalidade.

Enfim, as relações entre o design da embalagem e seu ciclo de vida estão inscritas em contextos sociais e políticos, do ponto de vista do projeto, da produção, do uso e do pós-uso (Santos, 2003; Smith e White, 2000). Dar valor ao objeto em fim de vida significa integrar a idéia de ciclo na fabricação de produtos e suas embalagens. Isto implica que, aos poucos, todos os produtos manufaturados adquiram uma nova função essencial: a de serem valorizáveis. Idealmente, todos os elementos de um produto deveriam poder circular indefinidamente - ou pelo menos durante um período tão longo quanto possível - nos sucessivos ciclos de utilização (Kazazian, 2005, Pereira, 2003; Smith e White, 2000).

O fim da vida dos produtos, por tanto tempo ignorado pelas empresas, tem sido agora considerado como uma responsabilidade ambiental ou uma oportunidade econômica, ou ambos (Palhares, 2003; Pereira, 2003; Wilt e Kincaid, 1997). Geyer e Jackson (2004) apresentam uma previsão otimista: no futuro, aquelas empresas que gerenciarem estrategicamente o fim da vida de seus produtos serão mais bem sucedidas, pois estarão criando simultaneamente valor econômico e ambiental, ou seja, uma oportunidade ganha-ganha. A maioria das cadeias produtivas, desta forma, não se encerrará com a venda e entrega do produto, mas incluirá a gestão do fim da vida dos produtos.

Para que isso ocorra, as empresas devem considerar a gestão do fim da vida não como uma forma de disposição organizada do produto, mas como um "circuito fechado", isto é, como estratégia de recuperação do valor econômico e ambiental (Kazazian, 2005; Pereira, 2003). A estratégia de fluxo fechado indica que a empresa controla a totalidade do ciclo de vida do produto, notadamente seu fim de vida (Kazazian, 2005; Smith e White, 2000).

\subsection{Quem é o responsável pelo fim da vida das embalagens?}

Na gestão de resíduos sólidos, é necessário distinguir três grupos de atores sociais que estão interligados na solução do problema: 1) o poder público que pode estabelecer políticas públicas para gestão de resíduos e tributação da cadeia produtiva; 2 ) a população que precisa ser conscientizada, quanto aos benefícios da redução do lixo jogado fora, e da reciclagem; e 3) a cadeia produtiva que pode desenvolver estratégias e táticas para a gestão do processo de reversão das embalagens ao ciclo produtivo (Grimberg, 2005).

Contrariamente às primeiras legislações do início dos anos 70, cuja tendência era responsabilizar os governos locais pelo impacto ambiental dos resíduos sólidos, uma das idéias básicas que orientam as legislações mais recentes é responsabilizar os fabricantes, direta e indireta- mente, pelo impacto de seus produtos no meio ambiente, por meio de leis dirigidas às etapas de reciclagem ou, indiretamente, por meio de proibição de disposição em aterros sanitários, de uso de certos tipos de embalagens plásticas até a devida estruturação de canais reversos (Leite, 2003; Manzini e Vezzoli, 2002). Essas legislações têm sua origem nas idéias da denominada filosofia de EPR (Extended Product Responsability), que significa responsabilizar a empresa produtora pelo ciclo de vida dos produtos que gera.

A tendência de estender a responsabilidade do produtor também para as fases finais dos produtos é uma das mais significativas tendências normativas, atualmente encontradas no cenário europeu e internacional. A União Européia decidiu aplicar o princípio do poluidor pagador, a fim de diminuir a quantidade dos resíduos que as empresas produtoras indiretamente criam (Kazazian, 2005; Williamson, 2000). Desde 1992, as empresas responsáveis pela comercialização de embalagens domésticas devem pagar um imposto cujo valor é fixado conforme o peso, o volume, o material e a reciclagem da embalagem (EUROPEAN COMMUNITIES COUNCIL, 1994). O produto dessa taxa serve ao financiamento da coleta seletiva dos resíduos de embalagens e à sua valorização. Trata-se de um processo que leva os produtores a se envolverem no fim de vida ecológico de seus produtos. Esta diretiva evidencia a tendência de procurar atribuir a responsabilidade aos produtores e demais integrantes da cadeia produtiva em implementar a gestão da logística reversa, estruturando e organizando os canais reversos de seus produtos (Williamson, 2000; Wilt e Kincaid, 1997).

No Brasil: a questão da geração e do descarte dos resíduos sólidos carece, ainda, de normatização. Foi criado, em 1998, o Programa Brasileiro de Reciclagem pelo Ministério da Indústria, Comércio e Turismo (MICT) para elaborar propostas gerais orientadoras nacionais, e um grande número de legislações tem sido discutido nas diversas esferas legislativas do País. Com base justamente na Diretiva Européia, tramita no Congresso Nacional Brasileiro um projeto de lei - Política Nacional de Resíduos Sólidos (2002) - que atribui à cadeia produtiva responsabilidade pela recuperação e reciclagem das embalagens descartadas pelo consumidor (Grimberg, 2005). Sendo a lei aprovada, as empresas brasileiras terão de mobilizar a cadeia produtiva, incluindo o consumidor, no sentido de recuperar as embalagens usadas.

\section{Logística reversa: equacionando o caminho de volta}

Existe uma clara tendência de que a legislação ambiental caminha no sentido de tornar as empresas cada vez mais responsáveis pelo ciclo de vida de seus produtos. O que significa ser responsável pelo destino de seus 
produtos após a entrega aos clientes e pelo impacto ambiental provocado pelos resíduos gerados em todo processo produtivo, e, também após seu consumo (Camargo e Souza, 2005).

Dessa forma, é necessário estruturar canais que facilitem o retorno de produtos ao ciclo produtivo, prática conhecida como logística reversa. Zikmund e Stanton (1971), já ressaltavam que "reciclagem consiste em encontrar novas formas de uso para o material previamente descartado" (p. 34). Entretanto, mesmo quando a reciclagem é tecnologicamente possível, o grande desafio é obter o fluxo reverso dos materiais pelos canais de distribuição. "Mais especificamente, reciclagem é primariamente um problema de canais de distribuição, porque o maior custo da reciclagem do lixo é sua coleta, seleção e transporte" (p. 34).

De forma simplificada, logística reversa pode ser definida como o processo inverso à logística. Neste artigo, considera-se logística reversa a área que equaciona e operacionaliza o fluxo físico e as informações correspondentes de bens após seu consumo, descartados pela sociedade, que retornam ao ciclo produtivo pelos canais reversos específicos.

Neste sentido, os benefícios potenciais da logística reversa podem ser agrupados em três níveis distintos. O primeiro refere-se às demandas ambientalistas que têm levado as empresas a se preocuparem com a destinação final de produtos e embalagens por elas gerados (Hu et al., 2002). O segundo é a eficiência econômica, já que a logística reversa permite a geração de ganhos financeiros pela economia no uso de recursos (Minahan, 1998). O terceiro nível está ligado ao ganho de imagem que a empresa pode ter perante seus acionistas, além de elevar o prestígio da marca e sua imagem no mercado de atuação (Roger e Tibben-Lembke, 1999; Daugherty et al., 2001).

Bowersox (2001) apresenta, por sua vez, a idéia de "apoio ao ciclo de vida", como um dos objetivos operacionais da logística moderna, referindo-se ao prolongamento da logística além do fluxo direto dos materiais e a necessidade de considerar os fluxos reversos de produtos em geral. A relação entre o ciclo de vida do produto e a Logística Reversa consiste em considerar o modo como se dará o descarte ou o reaproveitamento de peças e partes componentes do produto ao final do ciclo ainda no processo de desenvolvimento deles (Tibben-Lembke, 2002; De Britto, et al., 2002).

Assim, na definição dos materiais a serem utilizados, ainda na fase inicial de P\&D (Pesquisa e Desenvolvimento) deve ser considerada a possível reciclagem e reutilização dos materiais. Desta forma, por trás do conceito de logística reversa está o ciclo de vida do produto. A vida de um produto, do ponto de vista logístico, não termina com sua entrega ao cliente.

\section{Estratégias Metodológicas}

Esta pesquisa se inscreve no campo do estudo de caso e seu desenho está baseado em Yin (2005). A pesquisa exploratória é empregada nos casos em que não há um sistema de teorias e conhecimentos suficientes sobre o tema, sendo difícil elaborar hipóteses operacionalizáveis. Tais colocações subsidiam a escolha desta abordagem para o estudo da logística reversa e ciclo de vida da embalagem, já que há poucos trabalhos acadêmicos desenvolvidos no contexto brasileiro.

A coleta de dados se pautou tanto pelo levantamento de dados secundários sobre a cadeia reversa da embalagem PET, quanto pela realização de três entrevistas semi-estruturadas, durante os meses de agosto a outubro de 2005. As entrevistas foram gravadas e posteriormente transcritas para análise. Dos três entrevistados, dois deles mantêm vínculos com a Associação Brasileira das Indústrias de PET (ABIPET) e, neste artigo, serão denominados entrevistado 1 e entrevistado 2. O terceiro (entrevistado 3) é o presidente do Compromisso Empresarial para a Reciclagem (CEMPRE). Ambas as instituições são de caráter não-governamental, formadas a partir da congregação de empresas privadas, e têm como missão central a divulgação e a expansão dos processos de reciclagem no País, elegendo como alvo principal da atuação as indústrias brasileiras.

\section{A embalagem PET: aplicações e introdução no País}

O polímero de PET é um poliéster, desenvolvido pelos químicos ingleses Whinfield e Dickson em 1941. Obteve um rápido crescimento, inicialmente na substituição do algodão como fibra têxtil, e depois na década de 80 , na aplicação de filmes para embalagens. $\mathrm{O}$ entrevistado 2 esclarece que o PET é o nome que o mercado consagrou para o poliéster destinado à fabricação de embalagens, a mais comum delas destinada aos refrigerantes. Assim, o PET é um poliéster chamado de "grau garrafa" (bottle grade), em oposição ao seu semelhante utilizado na área têxtil, que é tratado como ou "grau fibra" (fiber grade). É preciso considerar que o poliéster "grau fibra" - usado na produção de fibras e filamentos - e o poliéster "grau garrafa" são produtos com a mesma base de matériasprimas, mas, que na sua fabricação, recebem aditivações diferentes, de acordo com o uso final pretendido.

A introdução da embalagem de PET no Brasil aconteceu em 1988, sendo que em 2004 foi o terceiro maior consumidor mundial de PET para produção de garrafas (ABIPET, 2005). Embora pareça que a tendência de crescimento do mercado de embalagens para refrigerantes esteja chegando ao limite, o crescimento do consumo aparente de PET no Brasil aumenta mais rapidamente que a produção, puxado 
pela entrada do polímero em novos segmentos alimentícios, como para embalar óleo, suco e água.

Contudo, um dos principais desafios tem sido sua reciclagem, caso incorretamente descartado, gera um grande impacto ambiental. O entrevistado 3 ressalta que "a atividade recicladora é fundamental para a sobrevivência da cadeia do PET, havendo duas motivações para o crescimento deste mercado: o apelo ecológico e a questão de custo".

\subsection{Embalagem PET: reciclando, a vida continua}

Na opinião do entrevistado 1 "para a cadeia do PET a reciclagem é muito importante e existe hoje [2005], após dez anos de atividade, uma indústria com seu próprio circuito. A matéria-prima reciclada já tem uma carteira de clientes cativos, os transformadores, que por sua vez, têm produtos feitos com a matéria prima reciclada". Atualmente, o polímero de PET é mais reciclado entre os plásticos em todo o mundo, devido a sua extensa gama de aplicações que vão das fibras têxteis a embalagens (entrevistado 2 ).

Do total de PET reciclado no Brasil em 2004, 37,1\% foi destinado à indústria têxtil, que é a principal aplicação para o produto (ABIPET, 2006). Outra parcela relevante foi destinada às cerdas monofilamentos para confecção de vassouras, embalagens para produtos de limpeza, carpetes e enchimentos de travesseiros. De acordo com o entrevistado 2, "a evolução da demanda por PET reciclado vem exigindo dos recicladores uma preocupação maior em oferecer um produto com melhor qualidade e, portanto, mais confiável para os usuários atuais e para as novas aplicações". Os esforços atuais estão direcionados no sentido de se obter um produto acabado de polímero reciclado que possua propriedades as mais próximas possíveis do polímero virgem, para ser empregado na confecção de materiais com aplicações mais nobres (Spinacé e Paoli, 2005).

No entanto, a legislação brasileira (Resolução $\mathrm{n}^{\circ}$ 105, ANVISA, 1999) veta a utilização de materiais plásticos procedentes de embalagens, fragmentos de objetos, materiais reciclados ou já utilizados, para produção de embalagens alimentícias. Contudo, no caso do PET, disponibiliza a utilização, em dependência de regulamentação de processos tecnológicos específicos para a obtenção destes materiais (Santos et al., 2004). Para este fim, foram desenvolvidas tecnologias conhecidas como "bottle-to-bottle" que envolvem etapas de lavagem, descontaminação, cristalização, pós-condensação no estado sólido e extrusão do PET (Spinacé e Paoli, 2005). O entrevistado 2 declara que "no Brasil já existem três plantas industriais produzindo através deste sistema, porém somente para embalagens destinadas ao segmento de higiene e limpeza".
Mesmo que a legislação fosse favorável, o entrevistado 1 vê obstáculos à utilização do PET reciclado para embalagens alimentícias no contexto brasileiro: "dificuldades de fiscalização, falta de coleta seletiva, catação em lixões e mistura do lixo seco e úmido na sua origem". Apesar das dificuldades listadas, fazendo um balanço do desempenho da indústria de reciclagem de PET no Brasil, a ABIPET (2006) mostra que, em 2004, o setor avançou $20 \%$, chegando à marca das 167 mil toneladas recicladas, ou seja, $47 \%$ do que foi produzido.

A situação brasileira é vista com otimismo:

[...] temos aqui uma mescla do modelo europeu e americano de reciclagem. Americano, pois temos empreendedores e empresários dispostos a investir na reciclagem. Europeu, por termos uma população cada vez mais consciente do seu papel na disposição correta do lixo. E, ainda, diferentemente destes mercados, temos aqui as questões sociais, que precisam ser mais bem compreendidas. Entretanto, o mercado brasileiro apresenta uma conjunção de fatores que faz com que a reciclagem caminhe muito bem (Entrevistado 1).

Desde o final dos anos 80 os catadores começaram a ocupar um papel cada vez mais importante num sistema informal de reciclagem e, por conseqüência, de coleta seletiva e gerenciamento dos resíduos domiciliares, no vácuo dos programas municipais oficiais, que quando existem, são restritos e sujeitos à descontinuidade e à alternância de interesses dos grupos políticos no poder (Jacobi e Viveiros, 2006). Os catadores são hoje os responsáveis pelos significativos índices de coleta seletiva no País, fazendo do Brasil um dos campeões mundiais em reciclagem (Campos, 2000). Em 2003, 80\% da coleta PET para reciclagem dependia do trabalho dos catadores (Czapski, 2003).

No caso das embalagens PET, fica sempre a indagação do que acontece a elas após o consumo. O CEMPRE (s.d.) contabiliza que somente as regiões metropolitanas do Brasil, com 15 milhões de domicílios e 50 milhões de pessoas, consumiram, em 2004, 6 bilhões de embalagens PET. Para esta instituição, o correto equacionamento da logística reversa das embalagens é que vai viabilizar a reciclagem de diversos materiais, inclusive o PET. Assim, as possibilidades de disfunção ou refunção da embalagem PET após seu consumo estão discutidas na próxima seção.

\subsection{O fim da vida da embalagem PET: dis- função ou refunção?}

$\mathrm{Na}$ visão do entrevistado 1, no momento do descarte: [...] o consumidor tem um papel fundamental, pois decide o que fazer com a embalagem. Ele pode jogar na rua, colocar na cesta de lixo sem 
separação, o que se caracterizaria uma disfunção, ou encaminhar para reciclagem, o que se constituiria uma refunção de várias maneiras. Quando tem coleta seletiva regular, pode encaminhar devidamente ou, quando não tem coleta seletiva, pode entregar para um catador ou levar a um Posto de Entrega do Voluntário (PEVs), ou mesmo doar para uma instituição.

Para o entrevistado 1, "se a coleta seletiva fosse bem estruturada, conseguir-se-ia mais PET com menos contaminação". Quando deixada num aterro sanitário, impermeabiliza as camadas em decomposição, prejudicando a circulação de gases e líquidos (CEMPRE, 2005). As embalagens PET não recicladas, no conceito de disfunção ficam nos aterros, nos lixões, nas praias, nas ruas e nos rios. Já aquelas que voltam ao ciclo produtivo pela reciclagem, constituem a "refunção", fechando o circuito. Na perspectiva do entrevistado 2, "reciclar PET é outro jeito de fabricar PET. Você pode fabricar PET a partir de matéria-prima virgem ou você pode fabricar PET a partir do próprio PET'. A cadeia reversa que possibilita a refunção à embalagem está graficamente representada na Figura 2.

A reciclagem mecânica é o modo mais convencional no Brasil para se recuperar o valor agregado do PET. Nela, os produtos plásticos são moídos, lavados, submetidos à secagem e reprocessados, dando origem a novos produtos (Zanin e Mancini, 2004). O processo de reciclagem apresenta três fases bastante evidentes: 1) recuperação: que vai do descarte até a composição de fardos de PET; 2) revalorização: que se finaliza com a moagem em flocos ou o beneficiamento em grãos; e 3) transformação: que resulta na aplicação do PET reciclado em produtos finais.

Os catadores coletam os materiais recicláveis em diversas fontes: ruas, condomínios, escritórios, comércio, em associações de bairro, entre outras. Esta atividade congrega pessoas que geralmente têm nesses materiais sua principal fonte de renda. Segundo o entrevistado 3, "as embalagens PET quando devidamente separadas, proporcionam para a cadeia de reciclagem o segundo melhor rendimento no comércio de sucata".

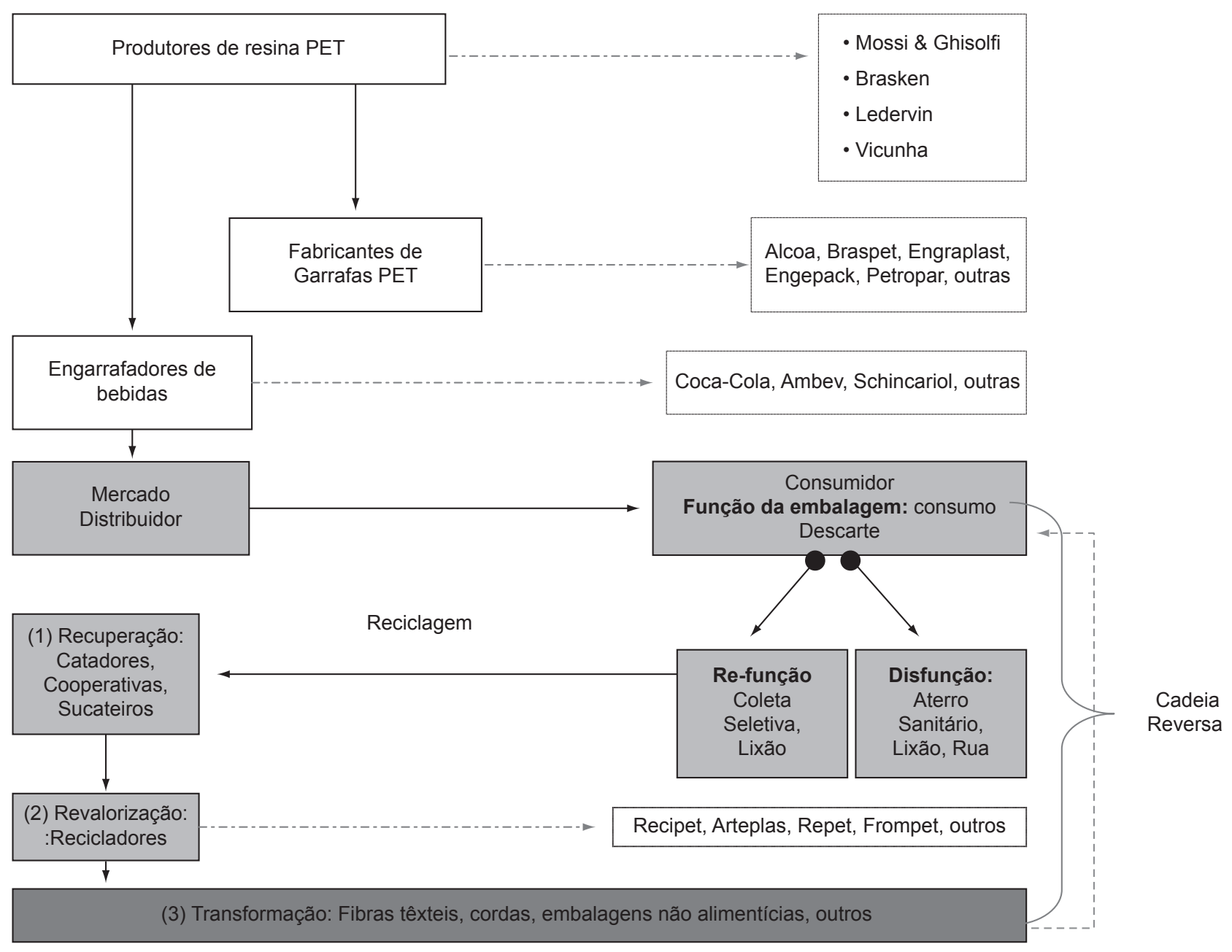

Figura 2. Cadeia Reversa das embalagens PET: uma visão do ciclo de vida no Brasil. Fonte: a partir de Leite (2003); Santos e Pereira (1999); ABIPLAST, ABIPET. 
A princípio, o PET deveria ser um dos plásticos mais fáceis de serem reciclados. Entretanto, várias limitações existem para a obtenção de produtos reciclados com alto valor agregado. Os principais contaminantes do PET, listados pelo CEMPRE/ABIPET (1997) são: cola, outros plásticos, em especial o PVC (Policloreto de Vinila), metais, areia e terra, além de ferrugem. Entretanto, o maior problema é a contaminação com PVC, pois ambos submergem na separação por densidades (DIAS, et al. 2004). Segundo o entrevistado 1, "uma garrafa de PVC pode inviabilizar a reciclagem de 20 mil garrafas de PET".

No caso do PET - novamente o problema da baixa densidade (volume grande e pequeno peso) - faz-se necessária a prensagem e enfardamento da sucata, pois, segundo o entrevistado 1, "o reciclador precisa da matéria-prima em grande quantidade". Então, após a coleta, os recicláveis são comprados por pequenos sucateiros e ferros-velhos, que são proprietários de área coberta ou não, na qual são acumulados estes materiais (CEMPRE, 2005). Após uma pré-seleção, os recicláveis são revendidos a grandes sucateiros, que possuem grandes depósitos, nos quais ocorre então uma separação manual ou mecânica para seleção dos diferentes tipos, retirada de impurezas em excesso e, em muitos casos, um pré-beneficiamento, dependendo do tipo de material. No caso das embalagens PET, elas devem ser prensadas, formando fardos (CEMPRE/ABIPET, 1997). "Outro obstáculo à expansão da reciclagem de materiais plásticos é a exigência de classificação dos diversos tipos de plásticos, que aumenta muito o custo da triagem" (entrevistado 3 ).

O entrevistado 2 destaca que o "sucateiro, apesar de fragilizar a remuneração dos catadores, não onera o preço para os elos subseqüientes da cadeia, pois o poder de barganha das grandes indústrias recicladoras e transformadoras é significativo". No meio da cadeia, encontram-se as recicladoras que são responsáveis pelo reprocessamento da embalagem PET, transformando-a em dois subprodutos: flocos e grãos. De acordo com o entrevistado 2:

[...] os recicladores especializados na produção de flocos são, em sua maioria, de pequeno porte, com a existência de algumas empresas de médio porte. Elas beneficiam os resíduos, através de separação manual, moagem, lavagem com água e secagem. Neste caso, há necessidade de grande quantidade de PET, em média 150 toneladas/mês, para tornar a atividade lucrativa, limitando a região geográfica para implantação da empresa.

Dados listados pela Plastivida (2005), mostram a existência de 126 empresas recicladoras de PET, concentradas nas Regiões Sudeste e Sul brasileiras em 2005. A concentração geográfica dessas empresas não significa níveis mais avançados de articulação entre elas, ao contrário do observado pelo entrevistado 3 a "cadeia reversa das latinhas de alumínio, que possui uma única planta de reciclagem no País e milhares de pontos de coleta, configuração viabilizada pelo alto valor agregado do alumínio".

Apesar de se beneficiar de toda a capilaridade da estrutura de catação já estabelecida para coleta de papéis e latas de alumínio, os recicladores de PET caracterizamse por pequenos empreendimentos pouco inovadores e reativos às legislações estabelecidas. Neste contexto, o entrevistado 2 ressalta que a realidade desta cadeia reproduz os fenômenos que se manifestam na indústria nacional, tais como, baixa tradição de investimento privado em pesquisa e desenvolvimento, dificuldade de obtenção de informações e distanciamento entre centros de pesquisa e empresas, principalmente as de pequeno e médio porte.

Aliás, os recicladores de plástico em geral alegam enfrentar uma série de entraves legais, dentre os quais o complexo modelo de competência administrativa (federal, estadual e municipal), a ausência de legislação específica sobre o manejo de lixo e a taxação federal do resíduo plástico, o único material reciclável que não é isento de IPI, que ainda sofre bi-tributação quanto ao ICMS (Calderoni, 1997). O entrevistado 1 alerta que "o impacto percebido pelas empresas recicladoras quanto ao papel do governo brasileiro é marcadamente de natureza de comando e controle, antes que de incentivo".

Por outro ângulo, a reciclagem mecânica, principal processo utilizado no Brasil na cadeia do PET, tem como principais vantagens: acessibilidade a pequenas e médias empresas, dado ao fato de ser uma tecnologia de fácil absorção, marcada pela baixa intensidade tecnológica; menor necessidade de mão-de-obra qualificada; e pequeno aporte de investimento demandado (entrevistado 1). Além disso, a reciclagem mecânica permite a reutilização do PET para um número variado de produtos e voltado a um mercado consumidor de amplo espectro, indo de baldes, vassouras, até roupas, materiais construtivos, que por sua vez apresentam um ciclo de vida mais longo do que as embalagens (CEMPRE, 2005).

Assim, um importante vetor de expansão é a demanda pelo reciclado, seja por motivações econômicas (custo) ou ecológicas. No caso do PET, existem maiores estímulos oriundos da indústria transformadora. A evolução do mercado e os avanços tecnológicos têm impulsionado novas aplicações para o PET reciclado das cordas e fios de costura aos carpetes, bandejas de frutas e até mesmo novas garrafas. No âmbito da indústria de transformação, uma das dificuldades é o tabu quanto à utilização do material reciclado (Czapski, 2003), dificultando a abertura de novas oportunidades de compra entre empresas aplicadoras que utilizam o PET para produtos de uso final, tais como tecidos. Além disso, a baixa confiabilidade da origem do reciclado, a indiferença entre matéria-prima vir- 
gem e reciclada e a pouca preocupação com o ecodesign são obstáculos à expansão da cadeia.

Finalmente, pode-se constatar que a reciclagem de materiais plásticos de embalagem pós-consumo, pela transformação em outros produtos, deve ser uma opção melhor explorada nas condições brasileiras, em face dos volumes disponíveis, possibilidade de aplicabilidade de tecnologias menos sofisticadas, amplo espectro de materiais disponíveis, existência de demanda e aceitabilidade no mercado interno de produtos fabricados com materiais reciclados, representando uma rota empresarialmente viável e ecologicamente correta.

\section{Considerações finais}

A orientação da gestão empresarial para uma atuação mais efetiva quanto aos processos finais do ciclo de vida de seus produtos exige a mobilização de conhecimentos técnicos e capacidade gerencial. No entanto, os maiores desafios encontram-se na reorientação das estratégias empresariais, de forma a incorporar de maneira consistente a análise da gestão do fim da vida das embalagens.

Para que isso ocorra, as empresas devem considerar a gestão logística, em conjunto com a gestão do fim da vida, não como uma forma de disposição organizada do produto, mas como um "circuito fechado", isto é, como estratégia de recuperação do valor econômico e ambiental. A estratégia de fluxo fechado indica que a empresa controla a totalidade do ciclo de vida do produto, notadamente seu fim de vida (Kazazian, 2005). Assim, o papel da logística reversa está no âmago da gestão do fim da vida das embalagens, devendo ser dirigido tanto pela oportunidade econômica como pela preocupação ambiental.

Entretanto, a empresa que se apropria da idéia de ciclo engendra uma verdadeira economia de recursos naturais. Ela repensa a transformação destes, valoriza os resíduos e inova por meio de novas estratégias de gestão. Obviamente, as estratégias de fluxo fechado necessitam de uma organização logística complexa e eficiente (Geyer e Jackson, 2004), ainda que seja apenas pela obrigação de manter uma relação direta com os clientes ou para atender à legislação cada vez mais rigorosa (Levy, 2000a). Todavia as vantagens são múltiplas e as oportunidades comerciais, evidentes. Nesta perspectiva, Geyer e Jackson (2004) defendem que é possível construir modelos de negócio lucrativos baseados na recuperação de valor econômico para o fim da vida de produtos.

A reciclagem do PET no Brasil enfrenta muitos dilemas e, por essa razão, apesar do seu rápido crescimento na última década, precisa superar alguns desafios de forma a se ampliar para níveis mais avançados em direção à sustentabilidade. As principais dificuldades com a coleta de PET dizem respeito à separação por coloração e tipo, devido a seus múltiplos usos e aplicações, e à contaminação por outros materiais plásticos, além de cola e sujeira. Também, a presença de atravessadores, os chamados "sucateiros", dificultam o avanço da qualidade do processo produtivo, quer seja na qualidade e confiabilidade da coleta, quer seja pela precarização da força de trabalho envolvida (os catadores), com nítidos obstáculos à sua maior profissionalização. Somam-se a isso as poucas iniciativas de coleta seletiva, em comparação com o universo urbano no País. Por fim, é urgente uma revisão das políticas públicas, tanto em termos tributários quanto da gestão dos resíduos urbanos.

Apesar destas dificuldades, a reciclagem do PET tem fortes apelos nas dimensões ecológica e econômica, além do seu papel social no Brasil. A capilaridade dos catadores como agentes da reversão das embalagens dos produtos consumidos torna mais amplo o alcance e a viabilidade dos volumes reciclados. Além de desafios de natureza sócio-econômica, a reciclagem tem também forte impacto nas estratégias gerenciais, exigindo novas configurações das relações que se estabelecem na cadeia de produção, consumo e reutilização de materiais, trazendo à tona uma necessidade de repensar a atuação e o papel da empresa frente a este cenário.

A indústria pode colaborar evitando a descontinuidade de compra, incentivando a capacitação de catadores, reduzindo intermediários e aumentando o valor do produto. Do outro lado, o setor público pode atuar no sentido de implantar boas práticas como a coleta seletiva, além dos incentivos à organização de cooperativas de catadores e um legislação que incentive a reciclagem. As iniciativas políticas, ao introduzirem sistemas de coleta seletiva de lixo, ou mesmo as empresas que fazem o marketing da reciclagem para neutralizar o impacto da produção de resíduos, merecem atenção da sociedade. Sendo mais imediata a visualização dos fluxos de matéria consumidos em curto prazo, tem-se a impressão de que algo está sendo feito para resolver o problema, e as questões realmente estruturais e de fundo ficam à margem (Grimberg e Blauth, 1998). Desta forma, é necessário maior investimento em informação e tecnologia. Levar ao grande público o conhecimento sobre a reciclagem dos materiais, instruindo sobre como proceder para o correto descarte das embalagens. Desenvolver tecnologias que permitam materiais de embalagem mais fáceis de reciclar, inofensivos e inertes, para proteção do meio ambiente, é outra importante frente de ação.

Nesse aspecto, o desejo efetivo de mudança da cultura organizacional adquire centralidade, trazendo à tona a necessidade de se repensar crenças, valores, posturas e práticas, que anteriormente se balizavam pelo foco no curto-prazo, pela ênfase na expansão ilimitada da produção e pela orientação para os processos internos da organização. Esses são grandes desafios empresariais em di- 
reção a um desenvolvimento de produtos ambientalmente mais responsável. O alcance de bons resultados nesse setor também depende de se investir em etapas anteriores e posteriores à reciclagem, ou seja, na coleta seletiva e no mercado para o produto reciclado. A atuação conjunta do governo, universidades, organizações não-governamentais e empresas pode criar um incentivo para o avanço da reciclagem no País.
Finalmente, quando se analisa a gestão estratégica do fim da vida da embalagem pode-se construir ferramentas essenciais que transcendem à sua reciclagem. Entretanto, faz-se necessário que em pesquisas futuras sejam desenvolvidas e analisadas bases metodológicas eficientes e adequadas à gestão ambiental do ciclo completo das embalagens, aí incluídos a concepção, a produção, o uso e o pós-consumo.

\section{Referências Bibliográficas}

ASSOCIAÇÃO BRASILEIRA DA INDÚSTRIA DE PET - ABIPET. Reciclagem. Disponível <http://www.abipet. org.br>[acesso em 10.09.2005].

$1^{\mathbf{0}}$. Censo da Reciclagem de PET no Brasil. São Paulo: ABIPET, outubro 2005. Disponível <http://www. abipet.org.br> [acesso em 24.06.2006].

ASSOCIAÇÃO BRASILEIRA DA INDÚSTRIA DO PLÁSTICO - ABIPLAST. Perfil da Indústria Brasileira de Transformação de Material Plástico - 2005. São Paulo: ABIPLAST, abril, 2006 Disponível: <http://www. abiplast.org.br> [acesso em 24.10.2006]

ASSOCIAÇÃO BRASILEIRA DE EMBALAGEM ABRE. Dados de mercado, 2006. Disponível <http:// www.abre.org.br> [acesso em 24.10.06]

AMADEU, F. B.; SARAN, G. M.; LORENZO, H. C.; CASTRO, M. C.; FONSECA, S. A. Políticas públicas e resíduos na "Região Araraquara - São Carlos". ENCONTRO NACIONAL DE GESTÃO EMPRESARIAL E MEIO AMBIENTE. Anais... Rio de Janeiro: EBAPE/FGV; EAESP/FGV; FEA/USP, 2005 [cd-rom].

BARRETT, E.; BICKERSTAFFE, J. Packaging's role in society. In: LEVY, G. (ed) Packaging, Policy and the Environment. Maryland: Aspen Publishers, 2000, p. 47-63.

BERTHIER, H. C. Garbage, work and society. Resources, Conservation and Recycling. US: Elsevier Science, v. 39, n.3, 2003, p. 193-210.

BRASIL. ANVISA. Agência Nacional de Vigilância Sanitária. Regulamento Técnico - Disposições Gerais para Embalagens e Equipamentos Plásticos em Contato com Alimentos. Resolução n. 105, de 19 de maio de 1999 - In: Diário Oficial da União, 20 maio 1999.

BRASIL. IBGE. Instituto Brasileiro de Geografia e Estatística. Pesquisa Nacional de Saneamento Básico PNSB2000. Ministério do Planejamento, Orçamento e Gestão, Rio de Janeiro, 2002, 397 p.

BOWERSOX, D. J. Logística empresarial: o processo de integração da cadeia de suprimentos. São Paulo: Atlas, 2001, 592 p.
CALDERONI, S. Perspectivas da reciclagem do lixo no município de São Paulo. Tese (Doutorado em Geografia Humana). São Paulo: FFCLH-USP, 1997.

CAMARGO, I.; SOUZA, A. E. Gestão dos resíduos sob a ótica da logística reversa. VIII Engema - Encontro Nacional de Gestão Empresarial e Meio Ambiente. Anais..., Rio de Janeiro, novembro, 2005.

CAMPOS, H. K. Projeto Lixo e Cidadania. Seminário de Resíduos Sólidos. São Paulo: Secretaria do Meio Ambiente, 10 a 12 de maio de 2000. Disponível em <http:// www.ambiente.sp.gov.br> [acesso em 20.10.2005]

CEMPRE - Compromisso Empresarial para a Reciclagem. Reciclagem de PET no Brasil, s.d. Disponível em: <http://www.ambientebrasil.com.br/> [acesso em 17/09/2004]

CEMPRE - Compromisso Empresarial para a Reciclagem. O sucateiro e a coleta seletiva. Reciclagem \& Negócios Mercado de Sucatas, CEMPRE, São Paulo, 2005. 32 p.

CEMPRE/ABIPET - Enfardamento e revalorização de sucatas de PET: Reciclagem \& Negócios, PET. São Paulo, 1997, $40 \mathrm{p}$.

CZAPSKI, SILVIA. Pet reciclado ainda é alvo de rejeição: indústria teme reação do público a fibras reaproveitadas. Valor Econômico: Valor online, São Paulo, ano 4, n. 911, 17 dez. 2003 [Empresa \& Comunidade].

DAUGHERTY, P. J.; AUTRY, C. W.; ELLINGER A. E. Reverse logistics: the relationship between resource commitment and program performance. Journal of Business Logistics, Lombard, IL: CSCMP, v. 22, n. 1, p. 107-123, 2001.

DE BRITTO, M. P.; FLAPPER, S. D. P.; DEKKER, R. Reverse logistics - a review of case studies. Econometric Institute Report, EI 2002-21, Rotterdam: Erasmus University, 21 Mai./2002.

DIAS, M. L; PACHECO, E. B. A.; NASCIMENTO, C. R.; SILVA, S. R.; FERNANDES, M. J. A. Uso de aditivos para melhoria das propriedades físicas de PET. Rio de 
Janeiro: Instituto de Macromoléculas Professora Eloísa Mano, Universidade Federal do Rio de Janeiro, 2004. Disponível <http://www.ufrj.br>, [acesso em 30.07.2005]

EUROPEAN COMMUNITIES COUNCIL. Diretiva 94/62/ EC: on Packaging and Packaging Waste. Official Journal of the European Communities, n. L349, p. 26 Brussels, 1994.

FONTEYNE, J. Packaging recovery and recycling policy in practice. In: LEVY, G. (ed) Packaging, Policy and the Environment. Maryland: Aspen Publishers, 2000, p. 205-247

GEYER, R. JACKSON, T. Supply loops and their constraints: the industrial ecology of recycling and reuse. California Management Review, v. 46, n. 2, Winter, 2004.

GRIMBERG, E. Governança democrática e um novo paradigma de gestão de resíduos sólidos. Instituto Polis, São Paulo, 02, mar. 2005. Disponível em $<$ http://www.polis. org.br> [acesso em 07.05.2005].

GRIMBERG, E.; BLAUTH, P. Coleta Seletiva: reciclando materiais, Reciclando valores. Polis: estudos, formação e assessoria em políticas sociais, n. 31, 1998.

HU, T. L. SHEU, J. B., HAUNG, K. H. A reverse logistics cost minimization model for the treatment of harzardous wastes. Transportation Research Part E, US. Elsevier Science, v. 38, 2002, p. 457-473.

IDEC - Instituto de Defesa do Consumidor. Do lixo quase tudo se aproveita. Revista do IDEC on line. Disponível em <http://www.idec.org.br> [acesso em 26.05.06]

JACOBI, P. Apresentação. In: JACOBI. P. (org.) Gestão compartilhada dos resíduos sólidos no Brasil : inovação com inclusão social. São Paulo: Annablume, 2006, p. 9-16.

JACOBI, P.; VIVEIROS, M. Da vanguarda à apatia, com muitas suspeitas no meio do caminho: gestão de resíduos domiciliares em São Paulo entre 1989 e 2004. In: JACOBI. P. (org.) Gestão compartilhada dos resíduos sólidos no Brasil: inovação com inclusão social. São Paulo: Annablume, 2006, p. 17-64.

KAZAZIAN, T. (org.). Haverá a idade das coisas leves: design e desenvolvimento sustentável. São Paulo: Editora Senac São Paulo, 2005, 194 p.

LEITE, P. R. Logística Reversa: meio ambiente e competitividade. São Paulo: Prentice Hall, 2003, 272 p.

LEVY, G. Introduction: Packaging, Policy and the environment. In: LEVY, G. (ed) Packaging, Policy and the Environment. Maryland: Aspen Publishers, 2000a, p. 1-46.

.Packaging in the environment: perceptions and realities. In: LEVY, G. (ed) Packaging, Policy and the
Environment. Maryland: Aspen Publishers, 2000b, p. 66-101.

MANZINI, E.; VEZZOLLI, C. O desenvolvimento de produtos sustentáveis: os requisitos ambientais dos produtos industriais.São Paulo: Edusp, 2002, 368 p.

MINAHAN, T. Manufactures take aim at end of the supply chain. Purchasing, US: Elsevier Science, v. 124, n. 6, Apr, 1998, p. 111-112 Disponível <http://www.purchasing.com> [acesso 25 março 2006].

PACHECO, E. B. Panorama da reciclagem de plásticos no Brasil. Seminário de Resíduos Sólidos Domiciliares. São Paulo: Secretaria do Meio Ambiente, 10 a 12 de maio de 2000. Disponível <http://www.ambiente.sp.gov. br [acesso em 03.03.2005].

PALHARES, M. F. P. O impacto do marketing "verde" nas decisões sobre embalagens das cervejarias que operam no Brasil. Dissertação [Mestrado em Administração] São Paulo: FEA/USP, 2003.

PEREIRA, A. F. Da sustentabilidade ambiental e da complexidade sistêmica no design industrial de produtos. Revista Estudos em Design. Rio de Janeiro: AEND, v. 10, n. 91, p. 37-36, 2003.

PEREIRA, A. F.; SANTOS, M. C. L. Design pré-reciclagem e pós-reciclagem:contribuição à discussão do problema do lixo urbano de embalagem, levando em conta a complexidade sistêmica da coleta e triagem. $1^{\circ}$. Congresso Internacional de Pesquisa em Design - Brasil. Anais... Brasília: Universidade de Brasíla, 2002.

PIETERS, R. Changing, garbage disposal patterns of consumers: motivation, ability, and performance. Journal of Public Policy and Marketing, US: AMA, v. 10, 1991.

PIVA, A. M.; WIEBECK, H. Reciclagem do plástico: como fazer da reciclagem um negócio lucrativo. São Paulo: Artiliber Editora, 2004, 112 p.

PLASTIVIDA. Reciclagem. Disponível <http://www.plastivida.org.br> [acesso em 06.09.2005].

POLÍTICA NACIONAL DE RESÍDUOS SÓLIDOS. Relatório Preliminar: minuta final. Ministério do Meio Ambiente: Brasília, versão II, 2002. Disponível em <http:// www.mma.gov.br> [acesso em 05.0 4.2005].

ROGERS, D. S.; TIBBEN-LEMBKE, R. S. Going backwards: reverse logistics trends and practices. Reno: University of Nevada, 1999, 393 p.

SANTOS, A. S. F.; AGNELLI, J. M., MANRICH, S. Tendências e desafios da reciclagem de embalagens plásticas. Polímeros - Ciência e Tecnologia, São Carlos (SP): ABIPOL, v. 4, n. 5, 2004, p. 307- 312.

SANTOS, M. C. L. Cidades de plástico e papelão: o habitat informal dos moradores de rua em São Paulo, Los 
Angeles e Tóquio. Tese [Livre Docência]. São Paulo: FAU/USP, 2003.

SANTOS, M. C. L.; PEREIRA, A. F. Packaging: function, re-function and malfunction. From consumer society to the homeless material culture. EcoDesign'99 - First International Symposium on Environmentally Conscious Design and Inverse Manufacturing. Anais... Tokyo, feb. 1999, p. 492-496.

SÃO PAULO. LIMPURB - Departamento de Limpeza Urbana. Caracterização dos Resíduos Sólidos Domiciliares do Município de São Paulo. São Paulo: Secretaria de Serviços e Obras, Prefeitura do Município de São Paulo, 2004.

SPINACÉ, M. A. S; PAOLI, M. A Tecnologia da Reciclagem de Polímeros. Química Nova, São Paulo: Sociedade Brasileira de Química, v. 28, n. 1, p. 65-72, 2005.

SMITH, C.; WHITE, P. Life Cycle assessment of packaging. In: LEVY, G. (ed) Packaging, Policy and the Environment. Maryland: Aspen Publishers, 2000, p. 178-204.

TIBBEN-LEMBKE, R. S. Life after death - reverse logistics and the product life cycle. International Journal of Physical Distribution and Logistics Management, v. 32, n. 3, 2002, p. 223-244.

WASIK, J. F. Green marketing and management: a global perspective. UK: Blackwell, 1996, 212 p.
WILLIAMSON, G. H. Packaging and environmental legislations: The european community. In: LEVY, G. (ed) Packaging, Policy and the Environment. Maryland: Aspen Publishers, 2000, p. 131-152.

WILT, C.; KINCAID, L. There auto be a law: end of life vehiche recycling policies in 21 countries, Resources Recycling, mar 1997.

WOODS, T. BEYNON, D. Managing the environmental impacts of packaging manufacture. In: LEVY, G. (ed) Packaging, Policy and the Environment. Maryland: Aspen Publishers, 2000, p. 153-177.

XAVIER, L. H. CARDOSO, R. Aspectos socioambientais da destinação dos resíduos plásticos. ENCONTRO NACIONAL DE GESTÃO EMPRESARIAL E MEIO AMBIENTE. Anais... Rio de Janeiro: EBAPE/FGV; EAESP/FGV; FEA/USP, 2005.

YIN, R. K. Estudo de Caso: Planejamento e métodos. $3^{\mathrm{a}}$ ed. - Porto Alegre: Bookman, 2005, 212 p.

ZANIN, M.; Mancini, S. D. Resíduos Plásticos e reciclagem: aspectos gerais e tecnologia. São Carlos: Edusfcar, 2004, 143 p.

ZIKMUND, W. G.; STANTON, W. T. Recycling solid wastes: a channels of distributions Problem. Journal of Marketing, US: AMA. v. 3, July, n.35, 1971, p. 34-39.

\title{
THERE IS LIFE AFTER DEATH: PACKAGING END-OF-LIFE STRATEGIC RETHINKING
}

\begin{abstract}
Solid waste is one of the most discussed topics on the agenda of environmental issues, especially in large urban centers. Many studies and scientific publications have focused on different phenomena related to the producing, collecting, disposing and recycling of urban waste, which leads to a growing concern about the destination of packaging after consumption. This article intends to promote a dialogue between reverse logistics and the packaging life cycle in order to better understand the possibilities, challenges and management dilemmas regarding the packaging end-oflife. It analyzes the recycling of PET (polyethylene terephthalate) packaging questioning the factors that promote and limit the expansion of environmental management strategies in Brazil. Recently, with multiple uses in the industrial production, PET has become a constant presence in consumers' daily routine and important challenges have arisen to understand the complex recycling chain and possibilities of more advanced practices and policies of environmental management. Developing the case study adopted different strategies, involving secondary data-collecting made by public organizations and specialized institutions as well as semi-structured interviews and analysis of documents. The results pointed out that although there are significant advances in the amount of recycling PET, there are important challenges to be overcome such as the laws that regulate the reverse chain, technological and management innovation strategies and mainly the interaction of chain actors. Furthermore, it is possible to foresee that this issue assumes the increase of the population information level; elimination of waste since its conception, technological development, shared responsibilities, recycling and above all, the change of the present consumption behavior pattern.
\end{abstract}

Keywords: recycling, packaging life cycle, pet packaging, reverse logistics, environment management. 